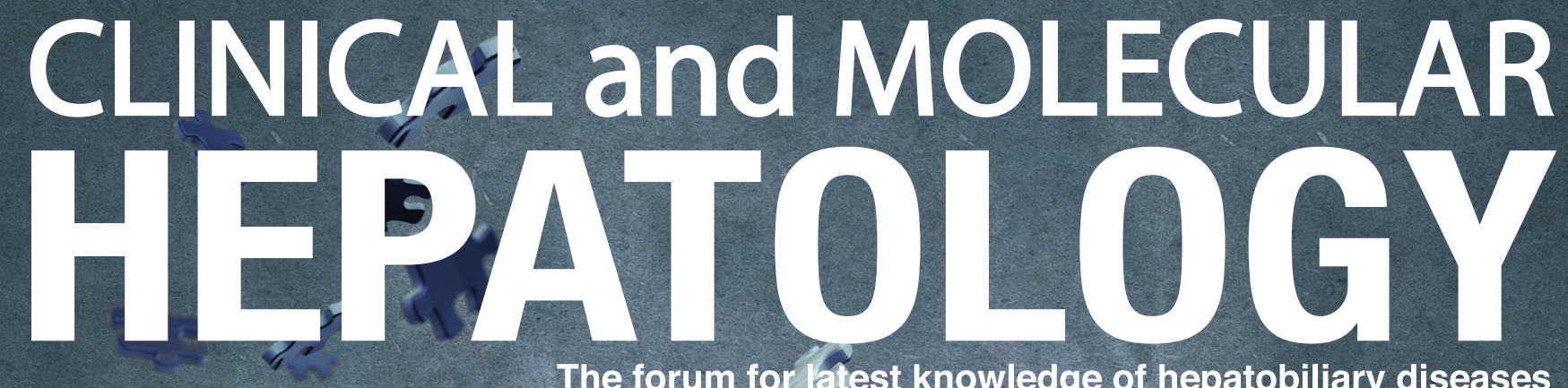

The forum for latest knowledge of hepatobiliary diseases

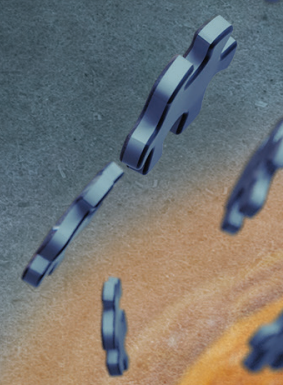

is

$$
\text { (n) }
$$

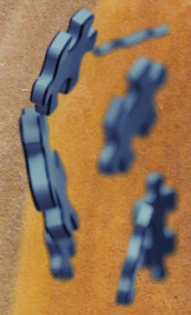

Fatty liver and risk of olementia

NAFLD increases a risk of siroke

DPP-4 inhibitor-specinic biornarkers in NAFID

LPS promotes HCC by NEE IS formation via TLRS4

CLIF-SOFA score and sepsis

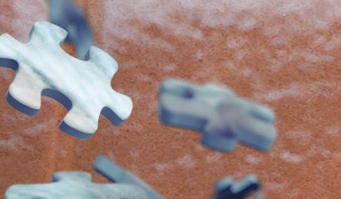




\title{
Statin and aspirin for chemoprevention of hepato- cellular carcinoma: Time to use or wait further?
}

\author{
Myung Ji Goh and Dong Hyun Sinn \\ Department of Medicine, Samsung Medical Center, Sungkyunkwan University School of Medicine, Seoul, Korea
}

Preclinical studies highlighted potential therapeutic applications of aspirin and statins as anticancer agents based on their pleiotropic effects. Epidemiologic studies suggested the role of aspirin and statins in the chemoprevention of hepatocellular carcinoma (HCC). However, observational data is prone to bias, and no prospective randomized trials are currently available to assess the risks and benefits of statin or aspirin therapy for chemoprevention of HCC. It is therefore important for clinicians and researchers to be aware of the quality of current evidence regarding this issue. In this review, we summarize currently available evidence to assist clinicians with their decision to use statin or aspirin and provide information for further clinical investigations. (Clin Mol Hepatol 2022;28:380-395)

Keywords: Statins; Aspirin; Hepatocellular carcinoma; Chemoprevention

\section{INTRODUCTION}

Hepatocellular carcinoma (HCC) is the third leading cause of cancer-related mortality worldwide, with growing incidence and mortality in both Western and Asian countries. ${ }^{1,2}$ HCC typically occurs in patients with chronic infections with hepatitis $B$ virus (HBV) and hepatitis $C$ virus (HCV), heavy alcohol intake and nonalcoholic fatty liver disease (NAFLD). ${ }^{3,4}$ The use of antiviral agents, such as nucleos(t)ide analogs (NAs) or direct-acting antivirals, has significantly decreased the complications of viral hepatitis-associated liver disease; however, it does not completely eliminate the risk of HCC in high-risk patients, including those with advanced fibrosis. ${ }^{5}$ Therefore, an effective strategy focused on preventing the development of HCC in at-risk population remains a clinical unmet need.
Recent experimental and epidemiological studies have highlighted the potential therapeutic applications of aspirin and statins as anticancer agents based on their anti-inflammatory, anti-proliferative, and pro-apoptotic effects, despite varying biological mechanisms of action. Long-term use of low-dose aspirin has been associated with a reduced risk of HCC in large-scale observational studies. ${ }^{6}$ Statins have also been suggested to reduce the risk of HCC in a number of observational studies and meta-analyses. ${ }^{7-9}$ However, they are often under-prescribed in patients with chronic liver disease or cirrhosis due to concerns of bleeding or hepatotoxicity. ${ }^{10,11}$ This review outlines current evidence of the chemopreventive effects of aspirin and statins, and provides a current perspective and prospect.

\footnotetext{
Corresponding author : Dong Hyun Sinn

Department of Medicine, Samsung Medical Center, Sungkyunkwan University School of Medicine, 81 Irwon-ro, Gangnam-gu, Seoul 06351, Korea Tel: +82-2-3410-3409, Fax: +82-2-3410-6983, E-mail: dh.sinn@samsung.com

https://orcid.org/0000-0002-7126-5554
}

Editor: Jian-Gao Fan, Xinhua Hospital Affiliated to Shanghai Jiaotong University School of Medicine, China 


\section{STATINS AND HCC}

\section{Mechanism of action}

Statins competitively inhibit 3-hydroxy-3-methylglutaryl coenzyme A (HMG-COA) reductase, blocking the conversion of HMG-COA to mevalonate, the rate-limiting step of cholesterol synthesis. As a consequence, statins prevent the synthesis of other important isoprenoid intermediates such as farnesyl pyrophosphate and geranyl pyrophosphate, and reduce intracellular cholesterol synthesis. These isoprenoid intermediates act as important lipid anchors for a variety of proteins including small guanosine triphosphate (GTP)-binding proteins. The pleiotropic effect of statins extends beyond cholesterol reduction and is mediated via inhibition of small GTPase isoprenylation and its downstream signaling pathway. ${ }^{12}$ Previous studies showed that statin treatment significantly decreased hepatic inflammation and fibrosis via inhibition of both RhoA/rho kinase and Ras/ERK pathways. ${ }^{13}$ The direct anti-inflammatory effect of statins was mediated via decreased levels of interleukin- 6 and downregulation of metalloproteinase activity in hepatocytes. ${ }^{14}$ In an animal model of nonalcoholic steatohepatitis (NASH), fluvastatin suppressed the activation and hepatic fibrogenesis of steatosisinduced hepatic stellate cells (HSCs) by decreasing the synthesis of reactive oxygen species (ROS), NF-KB activity and expression of pro-inflammatory genes including collagen, transforming growth factor- $\beta$, metalloproteinases- 1 , and alpha-smooth muscle actin. ${ }^{15}$ In cirrhotic rat models, atorvastatin downregulated noncanonical (Shh/RhoA) hedgehog signaling in HSCs and decreased fibrosis and portal pressure. ${ }^{16}$ Further, statins induced Krüppel-like factor-2 (KLF-2) in liver sinusoidal endothelial cells, resulting in vasoprotective response by inducing the expression of vasodilator and antithrombotic genes including endothelial nitric oxide synthase (eNOS) and thrombomodulin. ${ }^{17}$ KLF-2 also inhibits NF-KB transcriptional activity and regulates inflammation and fibrosis. ${ }^{18}$ In addition to their anti-inflammatory and anti-fibrotic effects, statins exhibit a direct chemopreventive effect by blocking oncogenic pathways including Ras-MAPK and PI3K/ Akt pathways. ${ }^{19,20}$ In addition, statins inhibit the activation of the proteasome pathway, limiting the degradation of cyclindependent kinase inhibitors p21 and p27 inducing G0/G1 cell cycle arrest. ${ }^{21,22}$ They block Myc phosphorylation, ${ }^{23}$ which results in the suppression of cancer proliferation. Furthermore, statins exert anti-angiogenic effect via impaired synthesis of pro-angiogenesis factors such as vascular endothelial growth factor. $^{24}$

\section{Epidemiologic studies: statins and HCC in general population}

A number of large-scale observational studies using nationwide cohort data have investigated the association between statin use and HCC risk in general population (Table 1). The first cohort study using a Danish National health service database of 348,262 individuals found no significant association between statin use and risk of any cancers including liver cancer (hazard ratio [HR], 1.16; 95\% confidence interval $[\mathrm{Cl}]$, 0.46-2.90). ${ }^{25}$ Post hoc analyses of 134,537 participants from 22 randomized controlled trials (RCTs) in the Cholesterol Treatment Trialists' collaboration investigating the role of statins in reducing cancer risk failed as well $(\mathrm{HR}, 1.06 ; 95 \% \mathrm{Cl}$, $0.65-1.70){ }^{26}$ However, these studies were limited by insufficient follow-up duration of less than 5 years and low incidence of primary liver cancer, which reduced the statistical power of the analysis of statin effects on primary liver cancer. Further, cancer development was a secondary outcome in all RCTs of statin use, which was not systematically investigated, thereby resulting in ascertainment bias.

A matched case-control study using a large cohort of Taiwan National Health Insurance Research Database found a significant inverse association between statin use and HCC (odds ratio [OR], 0.62; 95\% Cl, 0.42-0.91). ${ }^{27}$ Subsequent studies using large national cohorts including the Swedish Cancer Resister, UK's Clinical Practice Research Datalink and the Ko-

\footnotetext{
Abbreviations:

cDDDs, cumulative defined daily doses; Cl, confidence interval; CK, creatinine kinase; COX, cyclooxygenase; eNOS, endothelial nitric oxide synthase; Gl, gastrointestinal; GTP, guanosine triphosphate; HBV, hepatitis B virus; HCC, hepatocellular carcinoma; HCV, hepatitis C virus; HMG-COA, 3-hydroxy-3-methylglutaryl coenzyme A HR, hazard ratio; HSCs, hepatic stellate cells; KLF-2, Krüppel-like factor-2; NAFLD, nonalcoholic fatty liver disease; NAs, nucleos(t)ide analogs; NASH, nonalcoholic steatohepatitis; NIH-AARP, The National Institutes of Health-American Association of Retired Persons; NNT, number needed to treat; NSAIDs, non-steroidal antiinflammatory drugs; OR, odds ratio; RCTs, randomized controlled trials; ROS, reactive oxygen species; SAMS, statin-associated muscle symptoms; SVR, sustained virologic response; TXA2, thromboxane A2
} 


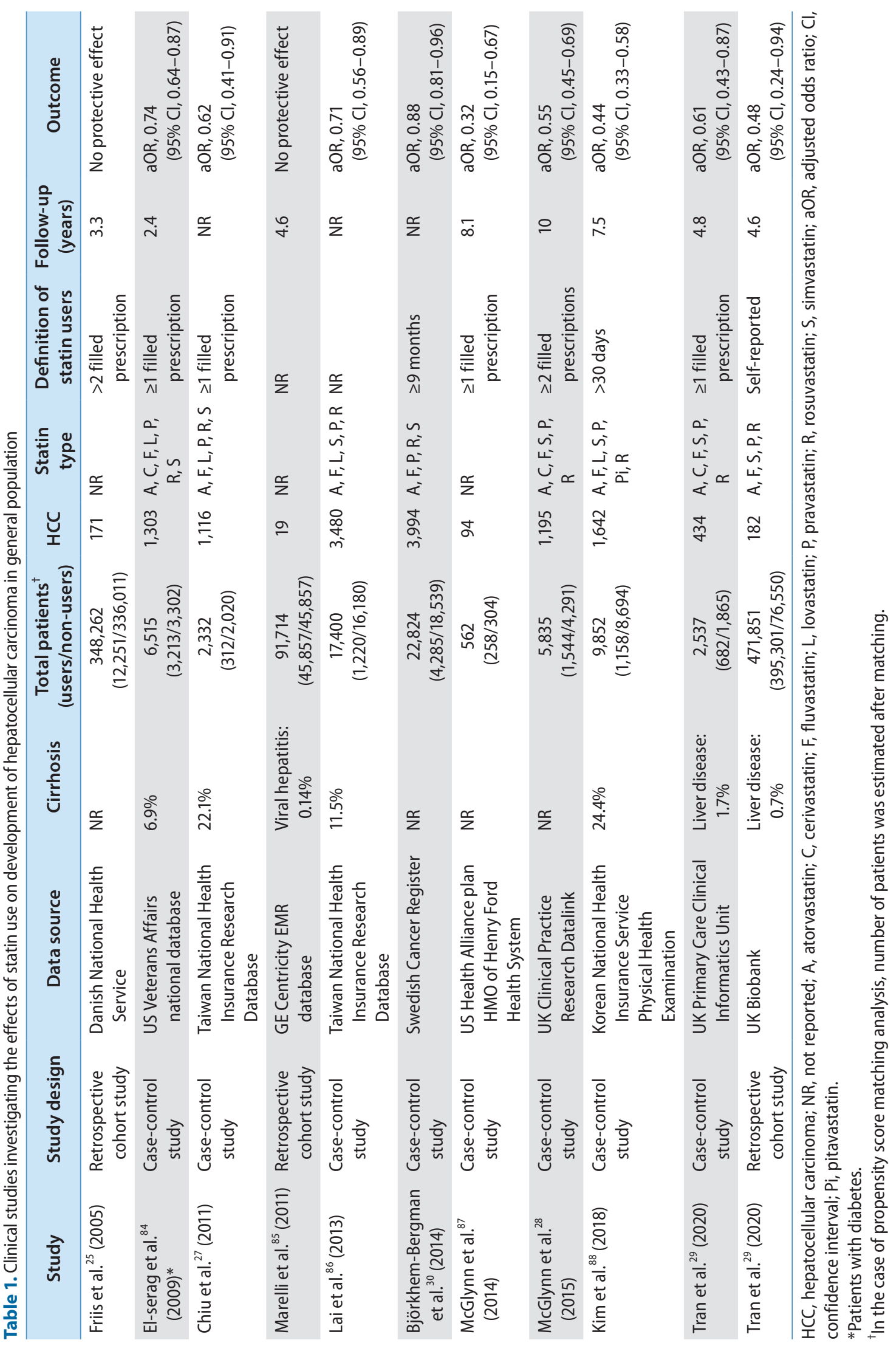


rean National Health Insurance consistently reported the chemopreventive effects of statins in HCC among the general population regardless of study location. ${ }^{28-30}$ Consistent with previous studies, a recent meta-analysis of 11 studies involving the general population reported a $46 \%$ reduction in HCC risk among statin users; however, substantial heterogeneity $\left(I^{2}=96.8 \%\right)$ was observed. ${ }^{31}$

\section{Epidemiologic studies: statin use and HCC in populations at risk}

The effects of statins were mainly assessed in patients diagnosed with viral hepatitis including HBV or HCV infections (Table 2). All investigations were performed in retrospective cohorts and no RCTs have been reported. The populationbased cohort study using the Taiwan National Health Insurance Reach Database first reported that statin use may reduce the risk of HCC in HBV-infected patients in a dosedependent manner (adjusted HRs, 0.66, 0.41, and 0.34 for statin use of 28 to 90,91 to 365 , and more than 365 cumulative defined daily doses [CDDDs], respectively). ${ }^{32}$ Subsequently, similar results were reported with 260,864 HCV-infected patients enrolled in the same database (adjusted HRs, 0.66, $0.47,0.33$ for statin use of 28 to 89,90 to 180 , and $>180$ cDDDs per year, respectively). ${ }^{33}$ Several studies, mostly performed in Asia, reported consistent findings. Furthermore, the protective effect of statin use was consistent or even more potent among patients with HBV treated with NA. ${ }^{34,35}$ Butt et al. ${ }^{36}$ investigated the impact of statins in patients who received HCV treatment in a longitudinal, national cohort of HCV-infected veterans, the electronically retrieved cohort of HCVinfected veterans. Statin was associated with a significant increase in sustained virologic response $(\mathrm{OR}, 1.44 ; 95 \% \mathrm{Cl}$, 1.29-1.61), a lower risk of progression to cirrhosis (HR, 0.56; $95 \% \mathrm{Cl}, 0.50-0.63)$ and $\mathrm{HCC}$ development $(\mathrm{HR}, 0.51 ; 95 \% \mathrm{Cl}$, 0.34-0.76). A meta-analysis of four studies consisting of either HBV- or HCV-infected patients found a significant risk reduction of $\mathrm{HCC}$ among statin users with low heterogeneity (pooled HR of patients with HBV, 0.54; $95 \% \mathrm{Cl}, 0.45-0.64$; $\mathrm{I}^{2}=37 \%$; pooled HR of patients with $\mathrm{HCV}, 0.47 ; 95 \% \mathrm{Cl}, 0.42-$ $\left.0.54 ;\left.\right|^{2}=0 \%\right)^{8}$

Few studies investigated the association between statin use and NAFLD-related HCC despite the indication for statin treatment in many of those patients. The most recent large retrospective study conducted at two tertiary academic cen- ters in the United States including 1,072 patients with NASHrelated advanced liver fibrosis reported a marked protective effect of statin use against HCC (HR, 0.40; $95 \% \mathrm{Cl}, 0.24-$ 0.67). ${ }^{37} \mathrm{~A}$ dose-dependent response was also observed among statin users with each yearly increment of CDDDs reducing the $\mathrm{HCC}$ risk by $23.6 \%$ compared with non-users.

A recent meta-analysis of pooled data based on contemporary observational studies involving the general population or at-risk population revealed no significant difference in risk reduction of HCC between general population and high-risk patients ( $\mathrm{HR}, 0.54 ; 95 \% \mathrm{Cl}, 0.42-0.89$ vs. $\mathrm{HR}, 0.52 ; 95 \% \mathrm{Cl}$, $0.37-0.73){ }^{31}$ In addition, a meta-analysis of six observational studies, which reported the proportion of cirrhotic patients, suggested a consistent HCC reduction regardless of cirrhosis. $^{38}$

\section{The effect of statin type}

Statins can be categorized into hydrophilic and lipophilic types depending on their solubility. The predominantly lipophilic statins (simvastatin, fluvastatin, pitavastatin, lovastatin, and atorvastatin) enter cells via passive diffusion and are widely distributed in tissues, whereas the uptake of hydrophilic statins (rosuvastatin and pravastatin) entails a liverspecific, carrier-mediated mechanism. ${ }^{39}$ Hence, it is hypothesized that lipophilic statins are more pleiotropic due to their non-lipid effects on extrahepatic tissue. Compared with hydrophilic statins, lipophilic statins not only prevent viral replication and stimulate antitumor immunity more effectively, ${ }^{40}$ but also show potent antitumor effects ${ }^{41}$ mediated by G0/G1 cell cycle arrest, inhibition of Ras/Raf/Mek/ERK signaling and apoptosis in preclinical studies. ${ }^{42,43}$

Consistent with preclinical data, a recent Swedish study using propensity score-matched cohort of 16,668 adults diagnosed with viral hepatitis in a nationwide population-based cohort reported that the use of lipophilic statins significantly reduced $\mathrm{HCC}$ incidence (HR, 0.56; 95\% $\mathrm{Cl}, 0.41-0.79)$. In contrast, no association between hydrophilic statin use and HCC risk was found ( $\mathrm{HR}, 0.95 ; 95 \% \mathrm{Cl}, 0.86-1.08) .{ }^{44}$ Findings from several observational studies and meta-analysis were in agreement with previous studies. ${ }^{45,46}$ Conversely, another meta-analysis of individual statin types reported that rosuvastatin, a hydrophilic statin, showed the most pronounced risk reduction in HCC development. ${ }^{7}$ The authors assumed that the higher affinity of rosuvastatin for HMG-COA reduc- 


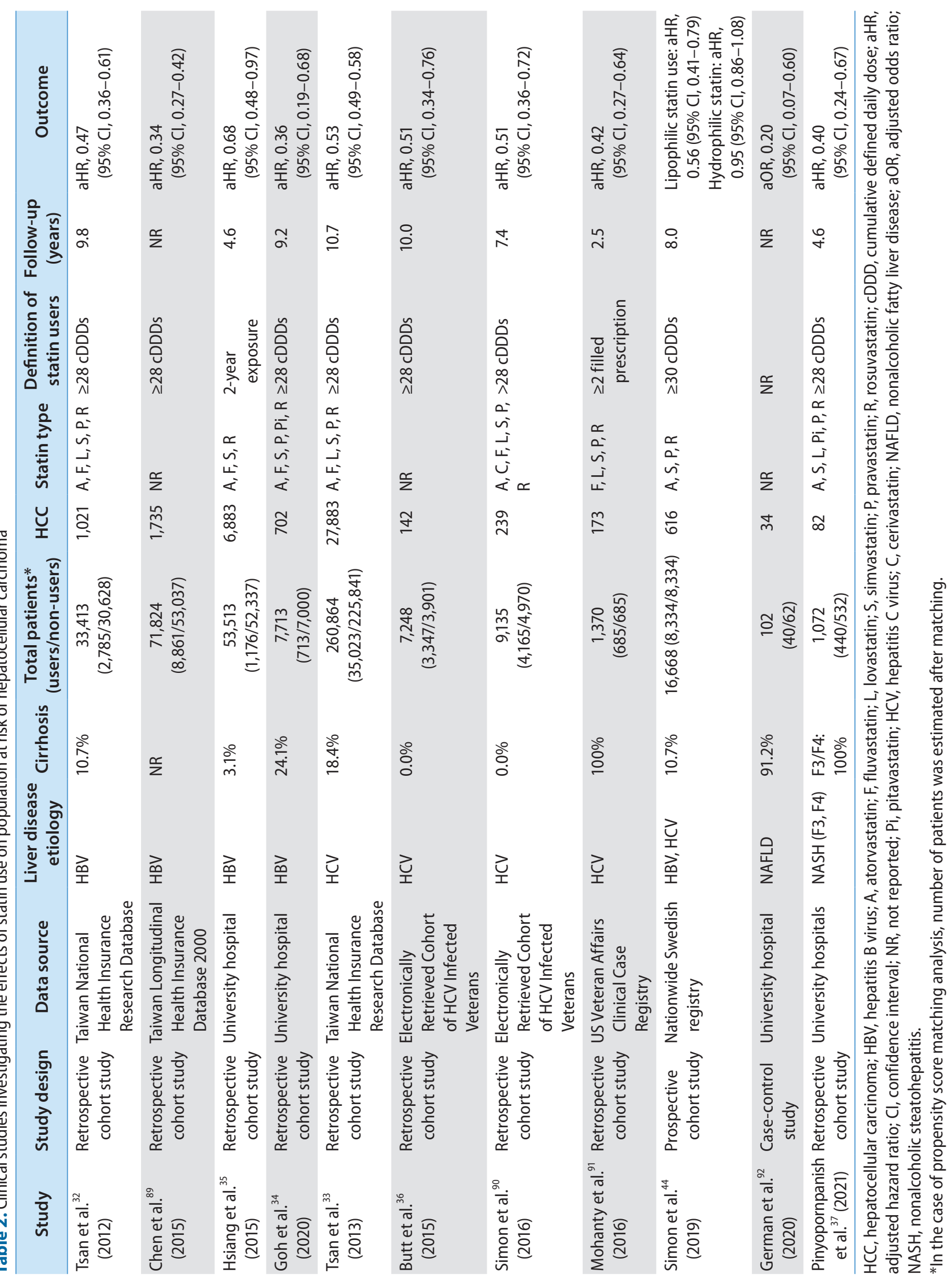


tase and a greater reduction in cholesterol level when compared to other statins resulted in greater therapeutic effects. ${ }^{7}$ Therefore, the beneficial effects related to statin solubility are not supported by robust evidence.

\section{The effect of statin dose and duration}

A higher dose of statin was associated with greater risk reduction of HCC development in most studies, while two studies from Hong Kong and Taiwan showed no significant dose-response relationship. ${ }^{27,35} \mathrm{~A}$ two-stage dose-response meta-analysis of six studies investigating statin use and primary liver cancer risk found that an increase in statin dose by every $50 \mathrm{cDDDs}$ per year reduced the risk of primary liver cancer by about $14 \%{ }^{47}$ Other dose-response meta-analyses comprising 11 studies found an interesting non-linear doseresponse curve suggesting a dose-response relationship between statin dose and a lower risk of primary liver cancer below 100 cDDDs annually or above 200 cDDDs each year. However, no such association existed between 100 and 200 cDDDs per year (HRs, $0.65,0.60,0.46$ and 0.22 for 55,200 , 320 , and 500 cDDDs per year, respectively). ${ }^{7}$ The biphasic effects of statins on angiogenesis described in preclinical studies strengthened their dose-dependent effect. ${ }^{48}$

\section{Safety of statin use}

Due to the risk of hepatotoxicity, physicians are less likely to prescribe statins for patients with liver disease. ${ }^{10,11}$ In fact, drug-induced liver injury related to statins is uncommon $(<1.2 / 100,000$ users $)$ and likely idiosyncratic in nature. ${ }^{49}$ In contrast, the most common toxicity associated with statins and the leading cause of statin discontinuation is statin-associated muscle symptoms (SAMS), which can manifest as myalgia, myopathy, myositis with elevated creatinine kinase (CK), or rhabdomyolysis. ${ }^{50}$ Despite the complex pathogenic mechanisms underlying SAMS, including mitochondrial toxicity, calcium signaling and genetic factors, ${ }^{50,51}$ the risk of SAMS appears to be linked to systemic exposure to higher doses. As a consequence, individuals with advanced cirrhosis may be at higher risk of SAMS due to increased drug exposure caused by delayed statin clearance, impaired CYP3A4 metabolism in the liver or diminished MRP2 membrane transporter activity. ${ }^{52}$

Several observational studies reported no significant differ- ences in drug-induced liver injury or myotoxicity between statin users and nonusers. ${ }^{33,53}$ In three of four small RCTs investigating the efficacy of statins on portal hypertension in patients with cirrhosis, no serious adverse events related to statins were reported. However, two patients receiving simvastatin $40 \mathrm{mg} /$ day experienced rhabdomyolysis in one RCT compared with none in the placebo group. ${ }^{54}$ The 2014 Assessments updated by the Liver Expert Panel of National Lipid Association Safety Task Force stated that chronic liver disease or compensated cirrhosis is not a contraindication to statin medication. Decompensated cirrhosis or acute liver failure, however, are contraindications for statin use. ${ }^{55}$

\section{Statin and HCC: level of evidence}

Statins provided consistent chemopreventive benefits against HCC in a variety of study designs with a heterogeneous population. An umbrella systematic review of 43 metaanalyses reported suggestive evidence for four malignancies in patients who used statins: esophageal cancer, hematological cancer, leukemia, and liver cancer. ${ }^{56}$

The number needed to treat (NNT) is a widely used metric of clinical benefit that reflects the number of patients who should be treated in order to avoid another adverse event, despite the possibility of misinterpretation depending on baseline risk for HCC. NNT was calculated in 5,209 East Asian males (incidence rate of HCC, 0.04 per 100 person-years) who needed statin therapy to prevent one $\mathrm{HCC}$ event per year and in 57 Asian men with HBV-associated cirrhosis who reported an estimated HCC incidence rate of 3.7 per 100 person-years according to a meta-analysis. ${ }^{9}$ It is assumed that those with the highest HCC risk are thought to benefit the most from statin chemoprevention.

However, observational studies have limitations due to confounding by indication, other residual confounders, selection bias and immortal time bias leading to overestimation of preventive effect of statins. ${ }^{57}$ Furthermore, safety issues should be addressed as the risk of statin-associated toxicity increases in high-risk individuals. Therefore, further prospective RCT data are needed including two ongoing clinical trials (NCT02968810 and NCT03024684) to establish the risk-benefit profile of statins for HCC prevention before they can be recommended for prevention. 


\section{ASPIRIN AND HCC PREVENTION}

\section{Mechanism of action}

Aspirin is an antiplatelet drug that inhibits both isoforms of cyclooxygenase (COX; COX-1 and COX-2), resulting in reduced levels of biologically active prostaglandins (PGE2, PGF2a, PGI2) and thromboxane A2 (TXA2). ${ }^{58}$ Low-dose aspirin (75$100 \mathrm{mg}$ ) inhibits COX1 irreversibly, whereas high-dose aspirin, similar to other non-steroidal anti-inflammatory drugs (NSAIDs), has analgesic and anti-inflammatory effects by nonspecifically inhibiting COX-2. ${ }^{58}$ Platelets have been shown to stimulate inflammatory and immune cells in immune-mediated inflammation induced by chronic viral hepatitis, facilitating tissue regeneration and carcinogenesis. In the animal model of chronic HBV infection, small and transient platelet aggregation is induced by microcirculation within the hepatic sinusoids, and these aggregates act as docking sites for circulating virus-specific CD8+ T lymphocytes, eventually triggering liver disease. ${ }^{59}$ Aspirin suppressed T-cell-mediated inflammation and HCC progression in the mouse model of chronic immune-mediated HCC, but failed to demonstrate a protective effect in a non-immunologically mediated, toxininduced HCC model. ${ }^{60}$ Furthermore, the proinflammatory COX-2 enzyme is overexpressed in cancer-related inflammation including HCC. Activation of COX increases prostaglandin synthesis, which may accelerate cellular proliferation, invasion, and angiogenesis. ${ }^{61}$ Aspirin may act as an antitumorigenic agent by decreasing platelet aggregation via TXA2 suppression and COX-2 inhibition, which reduces inflammation and induces cellular apoptosis. ${ }^{62}$

\section{Epidemiologic studies: aspirin and HCC in general population}

Since aspirin protects cardiovascular and cerebrovascular systems via anti-inflammatory and antithrombotic mechanisms, several randomized clinical trials were conducted in 1990s to investigate the effect of aspirin in the prevention of cardiovascular disease. Although such clinical trials were not designed to investigate the relationship between aspirin use and cancer risk, they were subsequently analyzed to determine the association between aspirin use and cancer risk. Despite conflicting results, a meta-analysis of participants from six RCTs of daily low-dose aspirin for primary prevention

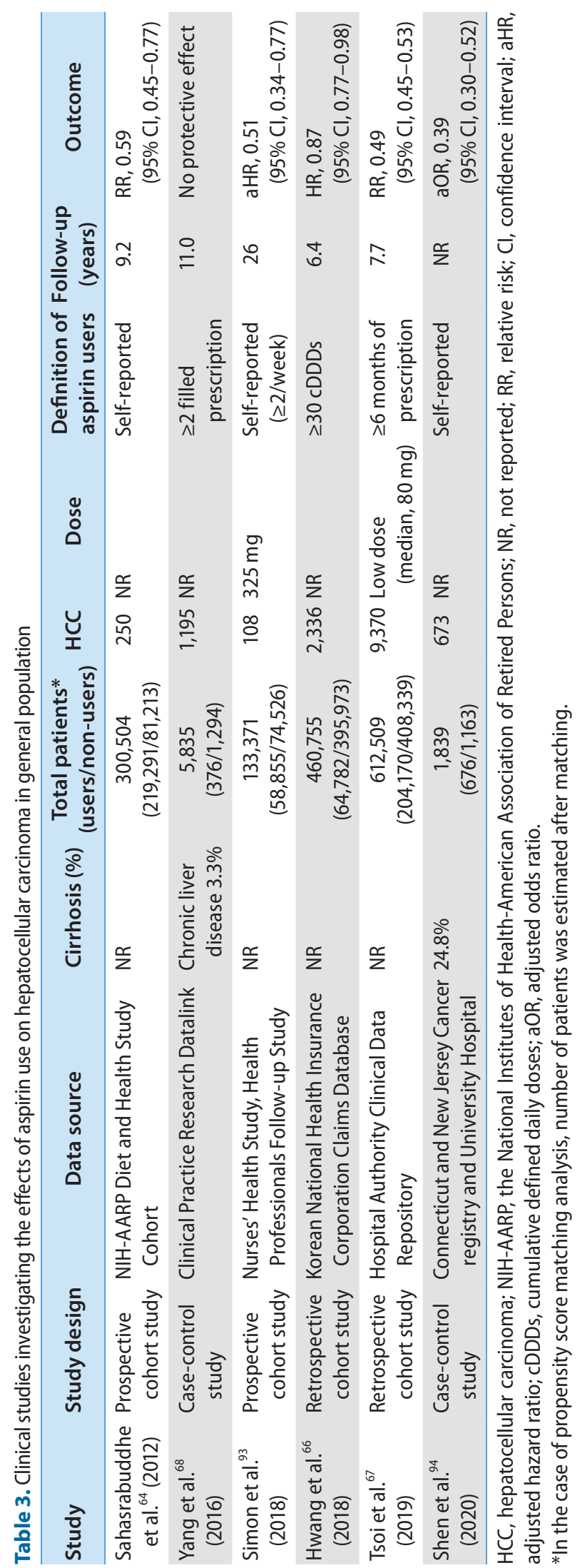


in the Antithrombotic Trialists' Collaboration (35,535 participants) reported a $19 \%$ reduction in cancer incidence among aspirin users compared with non-users after 3 years of use. ${ }^{63}$ However, due to limited sample size, the effect of aspirin on specific cancer types was not explored. Further studies into the chemopreventive effect of aspirin on HCC development were conducted in the general population (Table 3).

The National Institutes of Health-American Association of Retired Persons (NIH-AARP) Diet and Health study was the first to reveal that that aspirin users had a $41 \%$ lower risk of $\mathrm{HCC}$ than non-users. ${ }^{64}$ As part of the Liver Cancer Pooling Project, a large cohort study of 1,084,133 individuals from ten US-based prospective cohort studies demonstrated that taking aspirin reduced the risk of developing $\mathrm{HCC}(\mathrm{HR}, 0.68 ; 95 \%$ $\mathrm{Cl}, 0.57-0.81) .{ }^{65}$ Furthermore, large national cohort studies from Korea and Hong Kong, both high-risk geographic regions for HCC, found that long-term aspirin use reduced the risk of $\mathrm{HCC}$ by $13 \%$ and $51 \%$, respectively. ${ }^{66,67}$

In contrast, a nested case-control study using data from UK's Clinical Practice Research Datalink reported a lack of association between the use of NSAIDs including aspirin and liver cancer (OR, 1.11; 95\% Cl, 0.86-1.44). ${ }^{68}$ In contrast to previous studies that use self-reported data, this study relied on clinical prescription data to determine aspirin use. As aspirin is a widely available over-the-counter medication, particularly in the United States and regions of Europe, studies that rely on prescription claims or medical records may result in exposure misclassification. In fact, when compared with previous cohort studies utilizing self-reported aspirin, a substantially lower proportion of participants used aspirin (28\% vs. $73 \%) .{ }^{68}$

\section{Epidemiologic studies: aspirin and HCC in at- risk patients}

Recent investigations into the relationship between aspirin and $\mathrm{HCC}$ risk have mainly focused on patients with $\mathrm{HCC}$ risk factors such as viral hepatitis or cirrhosis (Table 4), which featured homogenous populations with a higher incidence of HCC. All investigations, similar to those exploring statins, were retrospective, and no RCTs were conducted.

A Korean hospital-based cohort study of 1,624 HBV patients receiving NA treatment reported that antiplatelet therapy was associated with a $56 \%$ risk reduction of HCC compared with non-use. ${ }^{69}$ Notably, aspirin use was an independent protective factor against $\mathrm{HCC}(\mathrm{HR}, 0.26 ; 95 \% \mathrm{Cl}$,
0.09-0.74), whereas neither clopidogrel nor dual antiplatelet therapy showed a significant association $(\mathrm{HR}, 0.63 ; 95 \% \mathrm{Cl}$, $0.15-2.65$ and $\mathrm{HR}, 0.67 ; 95 \% \mathrm{Cl}, 0.28-1.60$; respectively). ${ }^{69}$ Similar results were reported by a Taiwan national cohort study; however, the risk reduction was weaker than in the prior study (29\% vs. $74 \%$ ). ${ }^{70}$ The most recent cohort study of 35,111 Hong Kong HBV patients receiving NA treatment reported consistent findings as well as dose-response relationship (HR, $0.65,0.63$, and 0.41 for $0.25-2,2-5$, and $\geq 5$ years, respectively). ${ }^{71}$

According to a cohort study based on Taiwan's National Health Insurance database, aspirin lowered HCC risk in HCV patients by about $50 \% .^{72}$ A subsequent Taiwanese cohort study with a higher proportion of HCV-related cirrhotic patients reported consistent findings ( $\mathrm{HR}, 0.78 ; 95 \% \mathrm{Cl}, 0.64$ 0.95 ) but no statistical significance was observed in cirrhotic subgroup (HR, 0.75; 95\% Cl, 0.55-1.03)..$^{73}$ Finally, a Swedish nationwide registry-based study in chronic viral hepatitis concluded that low-dose aspirin reduced the risk of HCC and liver-related mortality $(\mathrm{HR}, 0.69 ; 95 \% \mathrm{Cl}, 0.62-0.76$ and $\mathrm{HR}$, $0.73 ; 95 \% \mathrm{Cl}, 0.67-0.81$; respectively). ${ }^{6}$ The pooled adjusted HR from seven matched cohort and case-control studies $(n=1,799)$ involving adults with chronic liver disease showed that aspirin use significantly reduced the risk of HCC development $(\mathrm{HR}, 0.51 ; 95 \% \mathrm{Cl}, 0.36-0.72) .^{74}$

Subgroup analyses of a meta-analysis involving 2.5 million subjects did not significantly alter the risk of liver cancer between general populations $(\mathrm{HR}, 0.60 ; 95 \% \mathrm{Cl}, 0.56-0.63)$ and populations with liver disease $(\mathrm{HR}, 0.66 ; 95 \% \mathrm{Cl}, 0.55-0.80){ }^{75}$ Meanwhile, the impact on cirrhotic patients was mixed. Two analyses including a cirrhosis-only population revealed inverse association between low-dose aspirin and $\mathrm{HCC}$ risk $^{76,77}$ and subgroup analysis of the cirrhotic population (either compensated or decompensated) by Simon et al. ${ }^{6}$ showed consistent findings. In contrast, a subgroup analysis using Korean and Taiwanese National Health Insurance database found no association between aspirin and HCC in cirrhotic patients. ${ }^{66,69,70}$ Lastly, a recent meta-analysis of individuals with viral hepatitis demonstrated that aspirin use was associated with a lower risk of HCC but the risk reduction rate was lower than in non-cirrhotic patients ( $\mathrm{HR}, 0.85 ; 95 \% \mathrm{Cl}, 0.76-$ 0.95 and $\mathrm{HR}, 0.64 ; 95 \% \mathrm{Cl}, 0.50-0.83)^{78}$ 


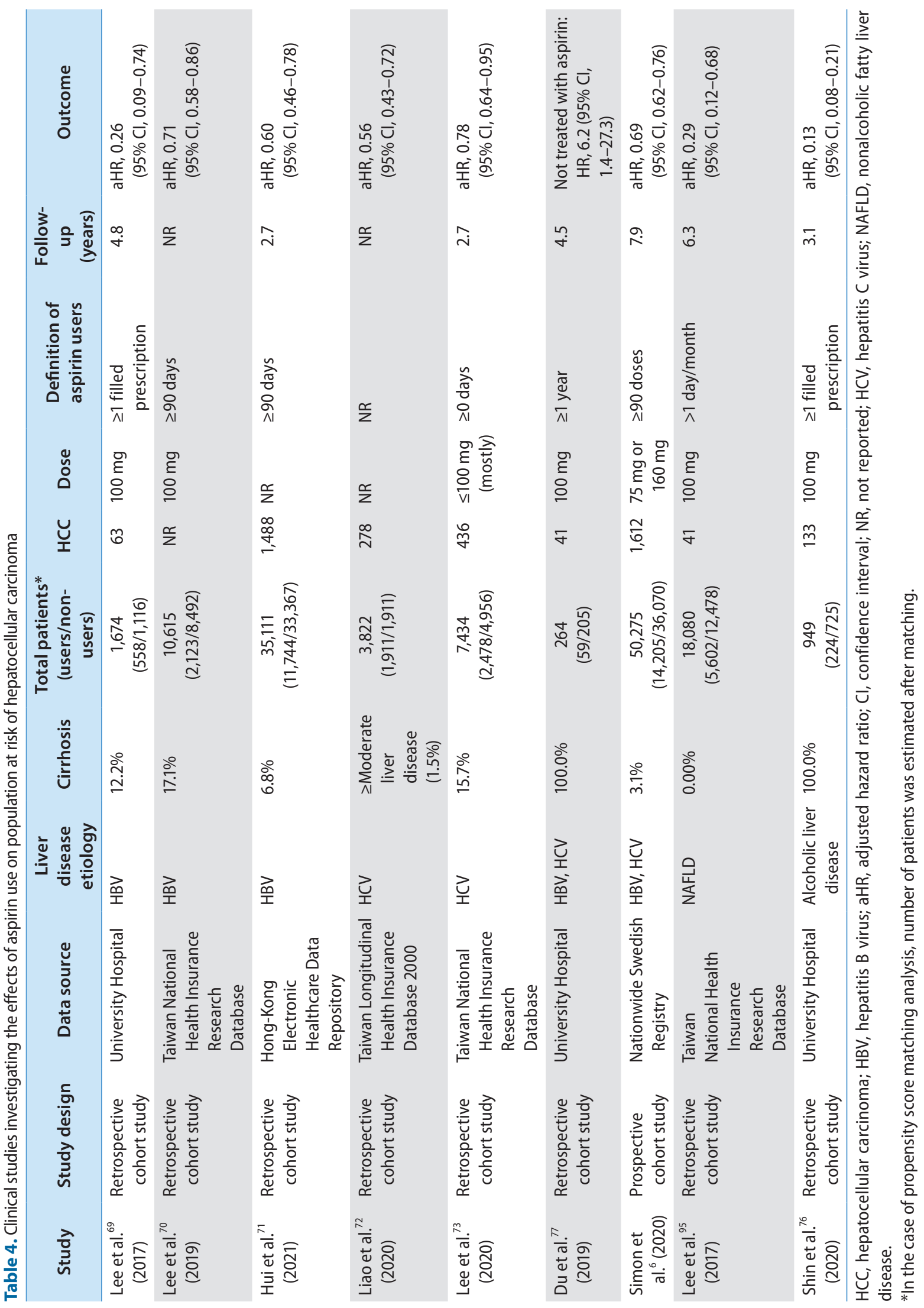




\section{Dose and duration}

Several studies reported that treatment with low-dose aspirin for a minimum of 3-12 months reduced the HCC risk. ${ }^{71,72}$ In contrast, the largest Swedish cohort study of viral hepatitis reported the most favorable outcome for low-dose aspirin after at least 5 years of continued usage, which was associated with a significant reduction in $\mathrm{HCC}$ incidence (HR, 0.58; 95\% Cl, 0.42-0.70) and mortality (HR, 0.63; 95\% Cl, 0.53$0.75) .{ }^{6}$ Based on dose-response analyses of four studies, each
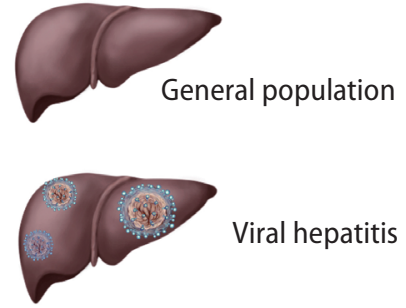

Compensated cirrhosis

Level of evidence: Moderate

A
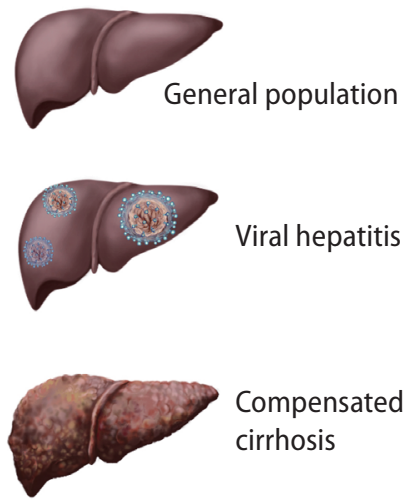

Compensated cirrhosis

Level of evidence: Moderate
Benefit

Statin

Risk

Common statin-associated muscle symptoms $(\sim 30 \%)$

Wide range of chemopreventive effect (no protective effect to $68 \%$ reduction)

Frequently elevated liver enzyme $(<3 \times \mathrm{ULN})(\sim 5 \%)$

Rare rhabdomyolysis $(\sim 0.001)$

Very rare severe liver injury $(<0.001 \%)$

Number need to treat: $5,209 \quad$ No significant difference

compare to general population

Number need to treat: 57

Largely remain safe

could increase risk of statin-related muscle toxicity due to change in pharmacokinetics

Chemoprevention (dose-dependent) (statin type [inconclusive])
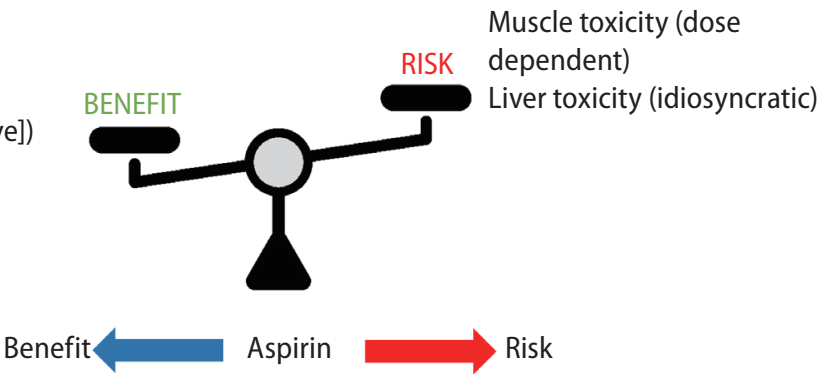

Wide range of chemopreventive effect

Major bleeding: $0.6 \%$ to $2.4 \%$

(No protective effect to $61 \%$ reduction) (over a 15-year period)

Number need to treat: 427

Most studies reported no significant difference compared to general population

But a few studies reported increased risk of any

Number need to treat: 128

Gl bleeding

B

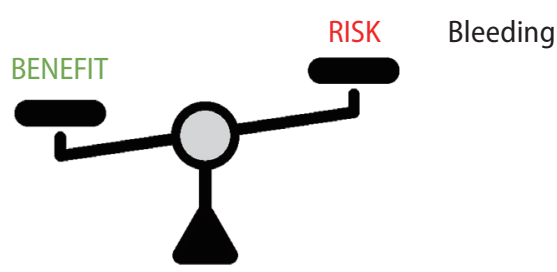

Figure 1. The key benefit-risk summary table with number needed to treat approach for (A) statins and (B) aspirin on chemoprevention of hepatocellular carcinoma. 
additional aspirin DDD contributed to a significant $0.02 \%$ reduction in HCC risk (adjusted RR, 0.98 ; $95 \% \mathrm{Cl}, 0.97-0.98$ ), corresponding to an $8.4 \%$ risk reduction per year of daily aspirin use. ${ }^{79}$ Another meta-analysis of daily dose response of aspirin based on eight cohort studies found that higher doses exceeding $100 \mathrm{mg} /$ day had no further chemopreventive benefit in incident $\mathrm{HCC}$ based on a non-linear model. ${ }^{75}$

\section{Safety issue}

The benefits of aspirin in primary prevention are offset by higher bleeding risks. ${ }^{80}$ Cirrhotic patients frequently manifest coagulation abnormalities and thrombocytopenia, which are associated with an increased risk of bleeding complications. Moreover, the exposure to NSAIDs including aspirin may precipitate hepatorenal syndrome by inducing renal vasoconstriction and lowering glomerular filtration rate. ${ }^{81}$ As a result of confounding by indication, data involving potential aspirin-related adverse events in patients with chronic liver disease were limited.

Four retrospective studies involving patients with chronic liver disease found a null association between daily aspirin use and increased risk of gastrointestinal (Gl) bleeding. ${ }^{6,69,73,76}$ However, a recent meta-analysis of four studies found that aspirin users had a $32 \%$ higher risk of Gl bleeding (HR, 1.32; $95 \% \mathrm{Cl}, 1.08-1.94)$ than non-users, and patients undergoing antiplatelet therapy (clopidogrel or dual therapy) had more than two-fold higher risk of $\mathrm{Gl}$ bleeding $(\mathrm{HR}, 2.62 ; 95 \% \mathrm{Cl}$, $1.20-5.85) .^{74}$ Interestingly, a recent study conducted in HBVinfected patients found a duration-dependent risk of GI bleeding after aspirin use. Patients taking aspirin for $\leq 2$ years had a substantially higher risk of Gl bleeding (HR, 1.73; 95\% $\mathrm{Cl}, 1.07-2.79)$ than those who did not take aspirin, but this risk decreased after 5 years of usage $(\mathrm{HR}, 0.79 ; 95 \% \mathrm{Cl}, 0.19-$ 3.21). ${ }^{71}$ Prophylactic usage of a proton pump inhibitor reduces the risk of GI bleeding; however, the risk of spontaneous bacterial peritonitis, hepatic encephalopathy, and Clostridium difficile infection is a concern. ${ }^{82}$

\section{Level of evidence}

According to the most recent meta-analysis, the pooled HRs from seven matched cohort and case-control studies $(n=51,799)$ investigating the association between aspirin use and $\mathrm{HCC}$ risk were $0.51(95 \% \mathrm{Cl}, 0.36-0.72)$ with moderate evidence based on GRADE certainty. Clinical heterogeneity due to differences in participant characteristics, aspirin dose, duration, concurrent medication usage, and follow-up duration reduced the level of certainty. ${ }^{74}$

Another meta-analysis of 19 observational studies involving a total of 2,389,019 individuals estimated that 427 adults with non-cirrhotic chronic HBV infection require aspirin treatment for 1 year to prevent one case of $\mathrm{HCC}$, assuming an $\mathrm{HCC}$ incidence rate of $0.6 / 100$ person-years. In the case of cirrhotic patients at a high risk for HCC, with an estimated annual incidence rate of $2 \%$, the NNT to prevent one case of HCC is $128 .^{79}$

However, the NNT in cirrhotic patients requires careful interpretation since the majority of studies investigating the impact of aspirin on HCC prevention in cirrhotic patients were conducted in Asia, with substantial differences in benefit ranging from $22 \%$ to $87 \%$. Furthermore, the increased bleeding risk among aspirin users is a clinically important issue in cirrhotic patients, who are at a higher risk of bleeding from esophageal varix, portal hypertensive gastropathy, and even life-threatening bleeding events such as intracranial hemorrhage. As a result, additional prospective RCTs are needed to overcome methodological limitations and to determine the target population for aspirin therapy, demonstrating that the benefits of chemoprevention outweigh the bleeding risks, before aspirin can be recommended as a chemopreventive agent in patients with chronic liver disease.

\section{CONCLUSION}

In this review, we have summarized the accumulating data on statins and aspirin for $\mathrm{HCC}$ chemoprevention, with a focus on the beneficial effects based on HCC risk, type, dose, and safety (Fig. 1). Statin and aspirin are expected to have a chemopreventive effect, and the potential benefits are supported by preclinical and epidemiological evidence. However, several issues remain to be addressed. First, the vast majority of studies are essentially retrospective in nature and associated with methodological challenges including confounding by indication, residual confounding, selection bias, measurement bias and exposure misclassification. Furthermore, the target population, dose and duration of aspirin and statins whose benefits overweigh harms such as aspirin-induced Gl bleeding or statin-associated myopathy were not conclusive. 
Accordingly, the level of evidence was moderate according to the Oxford Centre for Evidence-Based Medicine 2011 Levels of Evidence. ${ }^{83}$ Therefore, additional evidence from prospective RCTs is needed before either statin or aspirin therapy can be recommended for primary prevention of HCC. In contrast, statin or aspirin therapy is not a contraindication in patients with chronic liver disease or compensated cirrhosis and is certainly underutilized in real-life clinical practice. It may be early to use statin or aspirin for chemoprevention purpose. However, statin or aspirin therapy should be actively considered for patients with chronic liver disease or cirrhosis who are indicated for statin or aspirin therapy for other conditions such as prevention of cardiovascular disease.

\section{Authors' contribution}

MJG: Conceptualization and drafting of the manuscript. DHS: Study supervision and critical revision of the manuscript.

\section{Conflicts of Interest}

The authors have no conflicts to disclose.

\section{REFERENCES}

1. Choi J, Han S, Kim N, Lim YS. Increasing burden of liver cancer despite extensive use of antiviral agents in a hepatitis B virusendemic population. Hepatology 2017;66:1454-1463.

2. Ferlay J, Soerjomataram I, Dikshit R, Eser S, Mathers C, Rebelo $M$, et al. Cancer incidence and mortality worldwide: sources, methods and major patterns in GLOBOCAN 2012. Int J Cancer 2015;136:E359-E386.

3. Global Burden of Disease Liver Cancer Collaboration, Akinyemiju T, Abera S, Ahmed M, Alam N, Alemayohu MA, et al. The burden of primary liver cancer and underlying etiologies from 1990 to 2015 at the global, regional, and national level: results from the Global Burden of Disease Study 2015. JAMA Oncol 2017;3:1683-1691.

4. Cho JY, Paik YH, Sohn W, Cho HC, Gwak GY, Choi MS, et al. Patients with chronic hepatitis $B$ treated with oral antiviral therapy retain a higher risk for HCC compared with patients with inactive stage disease. Gut 2014;63:1943-1950.

5. Kanwal F, Kramer J, Asch SM, Chayanupatkul M, Cao Y, El-Serag HB. Risk of hepatocellular cancer in HCV patients treated with direct-acting antiviral agents. Gastroenterology 2017;153:996- 1005.e1.

6. Simon TG, Duberg AS, Aleman S, Chung RT, Chan AT, Ludvigsson JF. Association of aspirin with hepatocellular carcinoma and liver-related mortality. N Engl J Med 2020;382:1018-1028.

7. Zhong GC, Liu Y, Ye YY, Hao FB, Wang K, Gong JP. Meta-analysis of studies using statins as a reducer for primary liver cancer risk. Sci Rep 2016;6:26256.

8. Wong YJ, Qiu TY, Ng GK, Zheng Q, Teo EK. Efficacy and safety of statin for hepatocellular carcinoma prevention among chronic liver disease patients: a systematic review and meta-analysis. J Clin Gastroenterol 2021;55:615-623.

9. Singh S, Singh PP, Singh AG, Murad MH, Sanchez W. Statins are associated with a reduced risk of hepatocellular cancer: a systematic review and meta-analysis. Gastroenterology 2013;144:323-332.

10. Rzouq FS, Volk ML, Hatoum HH, Talluri SK, Mummadi RR, Sood GK. Hepatotoxicity fears contribute to underutilization of statin medications by primary care physicians. Am J Med Sci 2010;340:89-93.

11. Blais P, Lin M, Kramer JR, El-Serag HB, Kanwal F. Statins are underutilized in patients with nonalcoholic fatty liver disease and dyslipidemia. Dig Dis Sci 2016;61:1714-1720.

12. Cai A, Zhou Y, Li L. Rho-GTPase and atherosclerosis: pleiotropic effects of statins. J Am Heart Assoc 2015;4:e002113.

13. Schierwagen R, Maybüchen L, Hittatiya K, Klein S, Uschner FE, Braga TT, et al. Statins improve NASH via inhibition of RhoA and Ras. Am J Physiol Gastrointest Liver Physiol 2016;311:G724G733.

14. Arnaud C, Burger F, Steffens S, Veillard NR, Nguyen TH, Trono D, et al. Statins reduce interleukin-6-induced C-reactive protein in human hepatocytes: new evidence for direct antiinflammatory effects of statins. Arterioscler Thromb Vasc Biol 2005;25:12311236.

15. Chong LW, Hsu YC, Lee TF, Lin Y, Chiu YT, Yang KC, et al. Fluvastatin attenuates hepatic steatosis-induced fibrogenesis in rats through inhibiting paracrine effect of hepatocyte on hepatic stellate cells. BMC Gastroenterol 2015;15:22.

16. Uschner FE, Ranabhat G, Choi SS, Granzow M, Klein S, Schierwagen $\mathrm{R}$, et al. Statins activate the canonical hedgehog-signaling and aggravate non-cirrhotic portal hypertension, but inhibit the non-canonical hedgehog signaling and cirrhotic portal hypertension. Sci Rep 2015;5:14573.

17. Marrone G, Russo L, Rosado E, Hide D, García-Cardeña G, GarcíaPagán JC, et al. The transcription factor KLF2 mediates hepatic endothelial protection and paracrine endothelial-stellate cell 
deactivation induced by statins. J Hepatol 2013;58:98-103.

18. Jha $\mathrm{P}$, Das $\mathrm{H}$. KLF2 in regulation of NF-KB-mediated immune cell function and inflammation. Int J Mol Sci 2017;18:2383.

19. Janicko M, Drazilova S, Pella D, Fedacko J, Jarcuska P. Pleiotropic effects of statins in the diseases of the liver. World J Gastroenterol 2016;22:6201-6213.

20. Kim G, Kang ES. Prevention of hepatocellular carcinoma by statins: clinical evidence and plausible mechanisms. Semin Liver Dis 2019;39:141-152.

21. Wang ST, Ho HJ, Lin JT, Shieh JJ, Wu CY. Simvastatin-induced cell cycle arrest through inhibition of STAT3/SKP2 axis and activation of AMPK to promote p27 and p21 accumulation in hepatocellular carcinoma cells. Cell Death Dis 2017;8:e2626.

22. Relja B, Meder F, Wilhelm K, Henrich D, Marzi I, Lehnert M. Simvastatin inhibits cell growth and induces apoptosis and G0/G1 cell cycle arrest in hepatic cancer cells. Int J Mol Med 2010;26:735-741.

23. Cao Z, Fan-Minogue H, Bellovin DI, Yevtodiyenko A, Arzeno J, Yang $Q$, et al. MYC phosphorylation, activation, and tumorigenic potential in hepatocellular carcinoma are regulated by HMGCoA reductase. Cancer Res 2011;71:2286-2297.

24. Dulak J, Józkowicz A. Anti-angiogenic and anti-inflammatory effects of statins: relevance to anti-cancer therapy. Curr Cancer Drug Targets 2005;5:579-594.

25. Friis S, Poulsen AH, Johnsen SP, McLaughlin JK, Fryzek JP, Dalton SO, et al. Cancer risk among statin users: a population-based cohort study. Int J Cancer 2005;114:643-647.

26. Cholesterol Treatment Trialists' (CTT) Collaboration, Emberson JR, Kearney PM, Blackwell L, Newman C, Reith C, et al. Lack of effect of lowering LDL cholesterol on cancer: meta-analysis of individual data from 175,000 people in 27 randomised trials of statin therapy. PLoS One 2012;7:e29849.

27. Chiu HF, Ho SC, Chen CC, Yang CY. Statin use and the risk of liver cancer: a population-based case-control study. Am J Gastroenterol 2011;106:894-898.

28. McGlynn KA, Hagberg K, Chen J, Graubard BI, London WT, Jick $\mathrm{S}$, et al. Statin use and risk of primary liver cancer in the Clinical Practice Research Datalink. J Natl Cancer Inst 2015;107:djv009.

29. Tran KT, McMenamin ÚC, Coleman HG, Cardwell CR, Murchie P, Iversen $\mathrm{L}$, et al. Statin use and risk of liver cancer: evidence from two population-based studies. Int J Cancer 2020;146:1250-1260.

30. Björkhem-Bergman L, Backheden M, Söderberg Löfdal K. Statin treatment reduces the risk of hepatocellular carcinoma but not colon cancer-results from a nationwide case-control study in Sweden. Pharmacoepidemiol Drug Saf 2014;23:1101-1106.
31. Chang $Y$, Liu $Q$, Zhou Z, Ding $Y$, Yang $M$, Xu W, et al. Can statin treatment reduce the risk of hepatocellular carcinoma? A systematic review and meta-analysis. Technol Cancer Res Treat 2020;19:1533033820934881.

32. Tsan YT, Lee CH, Wang JD, Chen PC. Statins and the risk of hepatocellular carcinoma in patients with hepatitis B virus infection. J Clin Oncol 2012;30:623-630.

33. Tsan YT, Lee CH, Ho WC, Lin MH, Wang JD, Chen PC. Statins and the risk of hepatocellular carcinoma in patients with hepatitis $C$ virus infection. J Clin Oncol 2013;31:1514-1521.

34. Goh MJ, Sinn DH, Kim S, Woo SY, Cho H, Kang W, et al. Statin use and the risk of hepatocellular carcinoma in patients with chronic hepatitis B. Hepatology 2020;71:2023-2032.

35. Hsiang JC, Wong GL, Tse YK, Wong VW, Yip TC, Chan HL. Statin and the risk of hepatocellular carcinoma and death in a hospital-based hepatitis B-infected population: a propensity score landmark analysis. J Hepatol 2015;63:1190-1197.

36. Butt AA, Yan P, Bonilla H, Abou-Samra AB, Shaikh OS, Simon TG, et al. Effect of addition of statins to antiviral therapy in hepatitis $C$ virus-infected persons: results from ERCHIVES. Hepatology 2015;62:365-374.

37. Pinyopornpanish K, Al-Yaman W, Butler RS, Carey W, McCullough A, Romero-Marrero C. Chemopreventive effect of statin on hepatocellular carcinoma in patients with nonalcoholic steatohepatitis cirrhosis. Am J Gastroenterol 2021;116:22582269.

38. Islam MM, Poly TN, Walther BA, Yang HC, Jack Li YC. Statin use and the risk of hepatocellular carcinoma: a meta-analysis of observational studies. Cancers (Basel) 2020;12:671.

39. Egom EE, Hafeez H. Biochemistry of statins. Adv Clin Chem 2016; 73:127-168.

40. Bader T, Korba B. Simvastatin potentiates the anti-hepatitis B virus activity of FDA-approved nucleoside analogue inhibitors in vitro. Antiviral Res 2010;86:241-245.

41. Menter DG, Ramsauer VP, Harirforoosh S, Chakraborty K, Yang P, Hsi L, et al. Differential effects of pravastatin and simvastatin on the growth of tumor cells from different organ sites. PLoS One 2011;6:e28813.

42. Spampanato C, De Maria S, Sarnataro M, Giordano E, Zanfardino M, Baiano S, et al. Simvastatin inhibits cancer cell growth by inducing apoptosis correlated to activation of Bax and downregulation of BCL-2 gene expression. Int J Oncol 2012;40:935941.

43. Kato S, Smalley S, Sadarangani A, Chen-Lin K, Oliva B, Brañes J, et al. Lipophilic but not hydrophilic statins selectively induce 
cell death in gynaecological cancers expressing high levels of HMGCoA reductase. J Cell Mol Med 2010;14:1180-1193.

44. Simon TG, Duberg AS, Aleman S, Hagstrom H, Nguyen LH, Khalili $\mathrm{H}$, et al. Lipophilic statins and risk for hepatocellular carcinoma and death in patients with chronic viral hepatitis: results from a nationwide swedish population. Ann Intern Med 2019;171:318-327.

45. Li X, Sheng L, Liu L, Hu Y, Chen Y, Lou L. Statin and the risk of hepatocellular carcinoma in patients with hepatitis $B$ virus or hepatitis C virus infection: a meta-analysis. BMC Gastroenterol 2020;20:98.

46. Facciorusso A, Abd El Aziz MA, Singh S, Pusceddu S, Milione M, Giacomelli L, et al. Statin use decreases the incidence of hepatocellular carcinoma: an updated meta-analysis. Cancers (Basel) 2020;12:874.

47. Yi C, Song Z, Wan M, Chen Y, Cheng X. Statins intake and risk of liver cancer: a dose-response meta analysis of prospective cohort studies. Medicine (Baltimore) 2017;96:e7435.

48. Weis M, Heeschen C, Glassford AJ, Cooke JP. Statins have biphasic effects on angiogenesis. Circulation 2002;105:739-745.

49. Björnsson E, Jacobsen El, Kalaitzakis E. Hepatotoxicity associated with statins: reports of idiosyncratic liver injury postmarketing. J Hepatol 2012;56:374-380.

50. Ward NC, Watts GF, Eckel RH. Statin toxicity. Circ Res 2019;124:328-350.

51. Study of the Effectiveness of Additional Reductions in Cholesterol and Homocysteine (SEARCH) Collaborative Group, Armitage J, Bowman L, Wallendszus K, Bulbulia R, Rahimi K, et al. Intensive lowering of LDL cholesterol with $80 \mathrm{mg}$ versus $20 \mathrm{mg}$ simvastatin daily in 12,064 survivors of myocardial infarction: a double-blind randomised trial. Lancet 2010;376:1658-1669.

52. Pose E, Trebicka J, Mookerjee RP, Angeli P, Ginès P. Statins: old drugs as new therapy for liver diseases? J Hepatol 2019;70:194202.

53. Kaplan DE, Serper MA, Mehta R, Fox R, John B, Aytaman A, et al. Effects of hypercholesterolemia and statin exposure on survival in a large national cohort of patients with cirrhosis. Gastroenterology 2019;156:1693-1706.e12.

54. Abraldes JG, Villanueva C, Aracil C, Turnes J, Hernandez-Guerra $\mathrm{M}$, Genesca J, et al. Addition of simvastatin to standard therapy for the prevention of variceal rebleeding does not reduce rebleeding but increases survival in patients with cirrhosis. Gastroenterology 2016;150:1160-1170.e3.

55. Bays H, Cohen DE, Chalasani N, Harrison SA, The National Lipid Association's Statin Safety Task Force. An assessment by the statin liver safety task force: 2014 update. J Clin Lipidol 2014;8:S47-S57.

56. Jeong GH, Lee KH, Kim JY, Eisenhut M, Kronbichler A, van der Vliet $\mathrm{HJ}$, et al. Effect of statin on cancer incidence: an umbrella systematic review and meta-analysis. J Clin Med 2019;8:819.

57. Shi M, Zheng H, Nie B, Gong W, Cui X. Statin use and risk of liver cancer: an update meta-analysis. BMJ Open 2014;4:e005399.

58. Lichtenberger LM, Vijayan KV. Are platelets the primary target of aspirin's remarkable anticancer activity? Cancer Res 2019;79:3820-3823.

59. Guidotti LG, Inverso D, Sironi L, Di Lucia P, Fioravanti J, Ganzer L, et al. Immunosurveillance of the liver by intravascular effector CD8(+) T cells. Cell 2015;161:486-500.

60. Sitia G, Aiolfi R, Di Lucia P, Mainetti M, Fiocchi A, Mingozzi F, et al. Antiplatelet therapy prevents hepatocellular carcinoma and improves survival in a mouse model of chronic hepatitis B. Proc Natl Acad Sci U S A 2012;109:E2165-E2172.

61. Wong RSY. Role of nonsteroidal anti-inflammatory drugs (NSAIDs) in cancer prevention and cancer promotion. Adv Pharmacol Sci 2019;2019:3418975.

62. Leng J, Han C, Demetris AJ, Michalopoulos GK, Wu T. Cyclooxygenase-2 promotes hepatocellular carcinoma cell growth through Akt activation: evidence for Akt inhibition in celecoxibinduced apoptosis. Hepatology 2003;38:756-768.

63. Rothwell PM, Price JF, Fowkes FG, Zanchetti A, Roncaglioni MC, Tognoni $G$, et al. Short-term effects of daily aspirin on cancer incidence, mortality, and non-vascular death: analysis of the time course of risks and benefits in 51 randomised controlled trials. Lancet 2012;379:1602-1612.

64. Sahasrabuddhe VV, Gunja MZ, Graubard BI, Trabert B, Schwartz LM, Park Y, et al. Nonsteroidal anti-inflammatory drug use, chronic liver disease, and hepatocellular carcinoma. J Natl Cancer Inst 2012;104:1808-1814.

65. Petrick JL, Sahasrabuddhe VV, Chan AT, Alavanja MC, BeaneFreeman LE, Buring JE, et al. NSAID use and risk of hepatocellular carcinoma and intrahepatic cholangiocarcinoma: the liver cancer pooling project. Cancer Prev Res (Phila) 2015;8:11561162.

66. Hwang IC, Chang J, Kim K, Park SM. Aspirin use and risk of hepatocellular carcinoma in a national cohort study of Korean adults. Sci Rep 2018;8:4968.

67. Tsoi KKF, Ho JMW, Chan FCH, Sung JJY. Long-term use of lowdose aspirin for cancer prevention: a 10-year population cohort study in Hong Kong. Int J Cancer 2019;145:267-273.

68. Yang B, Petrick JL, Chen J, Hagberg KW, Sahasrabuddhe VV, 
Graubard BI, et al. Associations of NSAID and paracetamol use with risk of primary liver cancer in the Clinical Practice Research Datalink. Cancer Epidemiol 2016;43:105-111.

69. Lee M, Chung GE, Lee JH, Oh S, Nam JY, Chang Y, et al. Antiplatelet therapy and the risk of hepatocellular carcinoma in chronic hepatitis B patients on antiviral treatment. Hepatology 2017;66:1556-1569.

70. Lee TY, Hsu YC, Tseng HC, Yu SH, Lin JT, Wu MS, et al. Association of daily aspirin therapy with risk of hepatocellular carcinoma in patients with chronic hepatitis B. JAMA Intern Med 2019;179:633-640.

71. Hui VW, Yip TC, Wong VW, Tse YK, Chan HL, Lui GC, et al. Aspirin reduces the incidence of hepatocellular carcinoma in patients with chronic hepatitis b receiving oral nucleos(t)ide analog. Clin Transl Gastroenterol 2021;12:e00324.

72. Liao YH, Hsu RJ, Wang TH, Wu CT, Huang SY, Hsu CY, et al. Aspirin decreases hepatocellular carcinoma risk in hepatitis $C$ virus carriers: a nationwide cohort study. BMC Gastroenterol 2020;20:6.

73. Lee TY, Hsu YC, Tseng HC, Lin JT, Wu MS, Wu CY. Association of daily aspirin therapy with hepatocellular carcinoma risk in patients with chronic hepatitis C virus infection. Clin Gastroenterol Hepatol 2020;18:2784-2792.e7.

74. Tan RZH, Lockart I, Abdel Shaheed C, Danta M. Systematic review with meta-analysis: the effects of non-steroidal antiinflammatory drugs and anti-platelet therapy on the incidence and recurrence of hepatocellular carcinoma. Aliment Pharmacol Ther 2021;54:356-367.

75. Wang S, Yu Y, Ryan PM, Dang M, Clark C, Kontogiannis V, et al. Association of aspirin therapy with risk of hepatocellular carcinoma: a systematic review and dose-response analysis of cohort studies with 2.5 million participants. Pharmacol Res 2020;151:104585.

76. Shin S, Lee SH, Lee M, Kim JH, Lee W, Lee HW, et al. Aspirin and the risk of hepatocellular carcinoma development in patients with alcoholic cirrhosis. Medicine (Baltimore) 2020;99:e19008.

77. Du ZQ, Zhao JZ, Dong J, Bi JB, Ren YF, Zhang J, et al. Effect of low-dose aspirin administration on long-term survival of cirrhotic patients after splenectomy: a retrospective single-center study. World J Gastroenterol 2019;25:3798-3807.

78. Li X, Wu S, Yu Y. Aspirin use and the incidence of hepatocellular carcinoma in patients with hepatitis $B$ virus or hepatitis $C$ virus infection: a meta-analysis of cohort studies. Front Med (Lausanne) 2021;7:569759.

79. Memel ZN, Arvind A, Moninuola O, Philpotts L, Chung RT, Corey
$\mathrm{KE}$, et al. Aspirin use is associated with a reduced incidence of hepatocellular carcinoma: a systematic review and metaanalysis. Hepatol Commun 2021;5:133-143.

80. Zheng SL, Roddick AJ. Association of aspirin use for primary prevention with cardiovascular events and bleeding events: a systematic review and meta-analysis. JAMA 2019;321:277-287.

81. Planas R, Arroyo V, Rimola A, Pérez-Ayuso RM, Rodés J. Acetylsalicylic acid suppresses the renal hemodynamic effect and reduces the diuretic action of furosemide in cirrhosis with ascites. Gastroenterology 1983;84:247-252.

82. Mak LY, Fung J. Proton pump inhibitors in chronic liver disease: accomplice or bystander? Hepatol Int 2020;14:299-301.

83. Howick J, Glasziou P, Greenhalgh T, Heneghan C, Liberati A, Moschetti I, et al. The 2011 Oxford CEBM Evidence Levels of Evidence (Introductory Document). Centre for EvidenceBased Medicine web site, <http://www.cebm.net/index. aspx?o=5653>. Accessed 20 Aug 2021.

84. El-Serag HB, Johnson ML, Hachem C, Morgana RO. Statins are associated with a reduced risk of hepatocellular carcinoma in a large cohort of patients with diabetes. Gastroenterology 2009;136:1601-1608.

85. Marelli C, Gunnarsson C, Ross S, Haas S, Stroup DF, Cload P, et al. Statins and risk of cancer: a retrospective cohort analysis of 45,857 matched pairs from an electronic medical records database of 11 million adult Americans. J Am Coll Cardiol 2011;58:530-537.

86. Lai SW, Liao KF, Lai HC, Muo CH, Sung FC, Chen PC. Statin use and risk of hepatocellular carcinoma. Eur J Epidemiol 2013;28:485-492.

87. McGlynn KA, Divine GW, Sahasrabuddhe VV, Engel LS, VanSlooten $A$, Wells $K$, et al. Statin use and risk of hepatocellular carcinoma in a U.S. population. Cancer Epidemiol 2014;38:523-527.

88. Kim G, Jang SY, Nam CM, Kang ES. Statin use and the risk of hepatocellular carcinoma in patients at high risk: a nationwide nested case-control study. J Hepatol 2018;68:476-484.

89. Chen Cl, Kuan CF, Fang YA, Liu SH, Liu JC, Wu LL, et al. Cancer risk in HBV patients with statin and metformin use: a population-based cohort study. Medicine (Baltimore) 2015;94:e462.

90. Simon TG, Bonilla H, Yan P, Chung RT, Butt AA. Atorvastatin and fluvastatin are associated with dose-dependent reductions in cirrhosis and hepatocellular carcinoma, among patients with hepatitis C virus: results from ERCHIVES. Hepatology 2016;64:4757.

91. Mohanty A, Tate JP, Garcia-Tsao G. Statins are associated with a decreased risk of decompensation and death in veterans with 
hepatitis C-related compensated cirrhosis. Gastroenterology 2016;150:430-440.e1.

92. German MN, Lutz MK, Pickhardt PJ, Bruce RJ, Said A. Statin use is protective against hepatocellular carcinoma in patients with nonalcoholic fatty liver disease: a case-control study. J Clin Gastroenterol 2020;54:733-740.

93. Simon TG, Ma Y, Ludvigsson JF, Chong DQ, Giovannucci EL, Fuchs CS, et al. Association between aspirin use and risk of hepatocellular carcinoma. JAMA Oncol 2018;4:1683-1690.
94. Shen Y, Risch H, Lu L, Ma X, Irwin ML, Lim JK, et al. Risk factors for hepatocellular carcinoma (HCC) in the northeast of the United States: results of a case-control study. Cancer Causes Control 2020;31:321-332.

95. Lee TY, Wu JC, Yu SH, Lin JT, Wu MS, Wu CY. The occurrence of hepatocellular carcinoma in different risk stratifications of clinically noncirrhotic nonalcoholic fatty liver disease. Int J Cancer 2017;141:1307-1314. 